\title{
Tellurite glasses for microstructured optical fibers manufacturing
}

\author{
Ryszard Stepien, ${ }^{* 1}$ Ryszard Buczynski, ${ }^{1,2}$ Dariusz Pysz, ${ }^{1}$ Ireneusz Kujawa, ${ }^{1}$ Monika Mirkowska ${ }^{1}$ \\ ${ }^{1}$ Institute of Electronic Materials Technology, 133 Wolczynska, 01-919 Warsaw, Poland \\ ${ }^{2}$ University of Warsaw, Department of Physics, 7 Pasteur, 02-093 Warsaw, Poland
}

Received March 19, 2010; accepted March 29, 2010; published March 31, 2010

\begin{abstract}
Two series of tellurite glasses synthesized in a $\mathrm{TeO}_{2}-\mathrm{WO}_{3}$ $\mathrm{PbO}-\mathrm{Na}_{2} \mathrm{O}-\mathrm{Nb}_{2} \mathrm{O}_{5}$ oxide system with variable contents of $\mathrm{WO}_{3}$ $(5 \div 38 \mathrm{~mol} \%)$ and $\mathrm{PbO}(0 \div 18 \mathrm{~mol} \%)$ are designed and manufactured Their transmission properties, thermal expansion coefficients and glass characteristic temperatures have been determined. The glasses with the highest resistance to recrystallization during thermal treatment have been selected. Fiber drawing tests are performed and confirmation of the usefulness of these out glasses in the manufacture photonic crystal fibers is obtained.
\end{abstract}

Most of the reported work devoted to nonlinear phenomena in photonic crystal fibers (PCFs) is related to silica glasses. Recently, a number of works devoted to soft glass based PCFs have been reported. The nonlinear refractive index of some of these glasses is up to 550 times higher than in the case of standard silica glass [1]. In particular, tellurite glasses are interesting for nonlinear applications due to their high linear and nonlinear refractive indices as well as their high transmittance in the visible and infrared ranges. Their nonlinear refractive index is two orders of magnitude higher than for silica and hard silicate glasses $[1,2]$. On the other hand, tellurite fibers cannot be monolithically integrated with silica fibers using the fusion splicing technique because of the mismatch between melting temperatures. Tellurite glasses have been successfully used in PCF development [3-5]. The optimization of tellurite glass composition for both high nonlinear refractive index and broadband transmission window is difficult due to problems related to their excessive crystallization susceptibility. It is well known for several types of soft glasses (silicate, borate, phosphate) that the transition from two-component systems to multi-component system can increase the thermal stability of glasses. This phenomenon is also confirmed for tellurite glasses. In this paper we report on the optical and thermo-mechanical properties of tellurite glasses synthesized in four- and five-component oxide systems with $\mathrm{TeO}_{2}, \mathrm{WO}_{3}, \mathrm{PbO}, \mathrm{Nb}_{2} \mathrm{O}_{3}$ and $\mathrm{Na}_{2} \mathrm{O}$.

The first test for tellurite glass synthesis is performed using the four component system $\mathrm{TeO}_{2}-\mathrm{WO}_{3}-\mathrm{Nb}_{2} \mathrm{O}_{5^{-}}$ $\mathrm{Na}_{2} \mathrm{O}$ based on the composition reported by Chillcce $a t$. al [5]. The glass composition labeled TWNB-01 with chemical composition $[\mathrm{mol} \%]$ : $71 \mathrm{TeO}_{2}, 22.5 \mathrm{WO}_{3}$,

*E-mail: ryszard.stepien@itme.edu.pl
$1.5 \mathrm{Nb}_{2} \mathrm{O}_{5}, 5 \mathrm{Na}_{2} \mathrm{O}$ was synthesized and used for fiber development. The TWNB-01 glass has very high refractive index $\mathrm{n}=2.22$ as well as a very high nonlinear refractive index $\left(\mathrm{n}_{2}=1.8 \times 10^{-19} \mathrm{~m}^{2} / \mathrm{W}\right.$ measured at $1240 \mathrm{~nm})$. Both capillaries and rods were successfully developed using casting and drawing methods.

To assist in the development of thermally stable tellurite glass with enhanced MidIR transmission, two additional series of glasses were selected for further study: TWPN/I and TWPN/II (Table 1). The main differences in their composition were related to the relative proportions of $\mathrm{WO}_{3}(5 \div 38 \mathrm{~mol} \%)$ and $\mathrm{PbO}(0 \div 18$ $\mathrm{mol} \%) . \mathrm{TeO}_{2}$ and $\mathrm{WO}_{3}$ were the main glass forming components, while $\mathrm{Na}_{2} \mathrm{O}$ and $\mathrm{Nb}_{2} \mathrm{O}_{5}$ played the role of glass lattice modifiers. $\mathrm{PbO}$ is used either as a modifier, in the case of the small concentration or it is used to create a lattice in the case of large concentration.

\begin{tabular}{|c|c|c|c|c|c|c|}
\hline \multirow{2}{*}{$\begin{array}{l}\text { Glass name/ } \\
\text { components }\end{array}$} & \multicolumn{6}{|c|}{ TWPN/I } \\
\hline & 1 & 2 & 3 & 4 & 5 & 6 \\
\hline $\mathrm{TeO}_{2}$ & 70 & 70 & 70 & 70 & 70 & 65 \\
\hline $\mathrm{WO}_{3}$ & 5 & 10 & 15 & 20 & 23 & 28 \\
\hline PbO & 18 & 13 & 8 & 3 & 0 & 0 \\
\hline $\mathrm{Na}_{2} \mathrm{O}+\mathrm{Nb}_{2} \mathrm{O}_{5}$ & \multicolumn{6}{|c|}{7} \\
\hline Glass name/ & \multicolumn{6}{|c|}{ TWPN/II } \\
\hline components & 1 & 2 & 3 & 4 & 5 & 6 \\
\hline $\mathrm{TeO}_{2}$ & 60 & 60 & 60 & 60 & 60 & 55 \\
\hline $\mathrm{WO}_{3}$ & 15 & 20 & 25 & 30 & 33 & 38 \\
\hline PbO & 18 & 13 & 8 & 3 & 0 & 0 \\
\hline $\mathrm{Na}_{2} \mathrm{O}+\mathrm{Nb}_{2} \mathrm{O}_{5}$ & \multicolumn{6}{|c|}{7} \\
\hline
\end{tabular}

Table 1. Chemical composition of the TWPN/I and TWPN/II series of glasses [mol\%]

High purity chemical reagents were used to prepare batches for glass melting. The glasses in $30 \mathrm{~g}$ portions were melted in a gold crucible within an electrical furnace in the air. After batch charging at $650^{\circ} \mathrm{C}$, the temperature is increased up to $800^{\circ} \mathrm{C}$ at a rate of $5^{\circ} \mathrm{C} / \mathrm{min}$. The glass melt is mixed with silica glass rods at temperatures of $750^{\circ} \mathrm{C}$ and $800^{\circ} \mathrm{C}$ and then it is held at a temperature of $800^{\circ} \mathrm{C}$ for 20 minutes. Subsequently, the glass melt at a temperature of $650^{\circ} \mathrm{C}$ is cast using a graphite mould heated up to $350^{\circ} \mathrm{C}$ and annealed at a rate of $0.5^{\circ} \mathrm{C} / \mathrm{min}$.

Measurements of glass transmittance were performed with the Broker IFS $113 \mathrm{~V}$ spectrophotometer over the range $2 \div 10 \mu \mathrm{m}$. The double-side polished samples of 4 
$\mathrm{mm}$ thickness were used for measurements. The measurement results of transmission for both series of glasses are shown in Fig. 1 and Fig. 2.

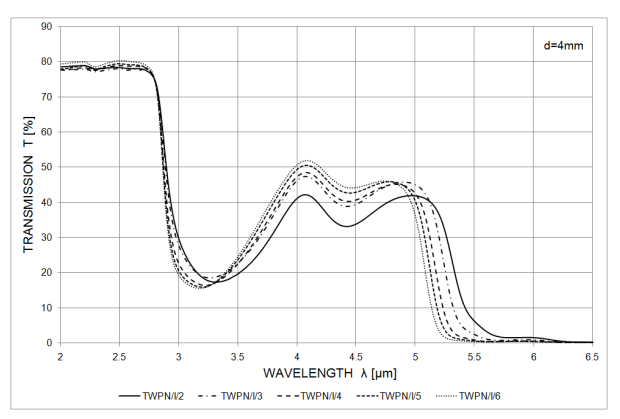

Fig.1. Transmittance of the TWPN/I series tellurite glasses in the range $2 \div 6,5 \mu \mathrm{m}$

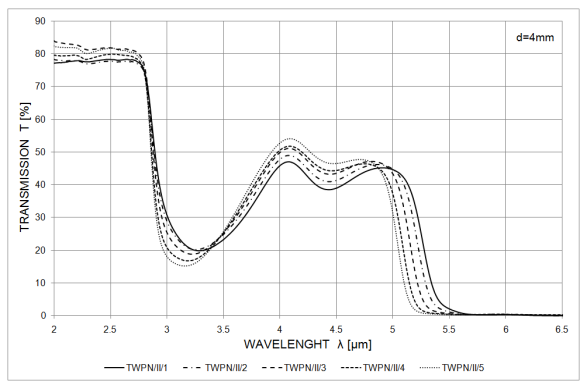

Fig. 2. Transmittance of the TWPN/II series tellurite glasses in the range $2 \div 6,5 \mu \mathrm{m}$

These results show that the chemical composition of glasses has a significant influence on transmittance in the infrared range 3-6 $\mu \mathrm{m}$. An increase in the $\mathrm{PbO}$ content causes a shift of the transmission spectrum towards the longer wavelengths. However, total transmittance decreases in this case. The strong absorption peak at $3.1 \div 3.3 \mu \mathrm{m}$ is related to the presence of $\mathrm{OH}^{-}$groups in glass. A decrease in the absorption is possible due to modified glass melting conditions: use of dry air or dry oxygen atmosphere, glass melt bubbling with dry oxygen or increase of melting time.

A dilatometer 801 Baehr Thermoanalyse was used to characterize linear thermal expansion coefficients. Rods with dimensions $4 \times 4 \times 30 \mathrm{~mm}$ were used for measurements. We have observed that the thermal expansion coefficient decreases monotonically with an increase of the $\mathrm{WO}_{3}$ content in the glass (Fig.3). A lower thermal expansion coefficient is an advantage in the case of PCF development since the glass is less sensitive to rapid temperature changes. It allows easier polishing and thermal processing of preform and subpreform components of PCFs.

The measured viscosity characteristics show that the tellurite glass is very soft and has a very limited temperature range where its forming is possible (Fig.4).

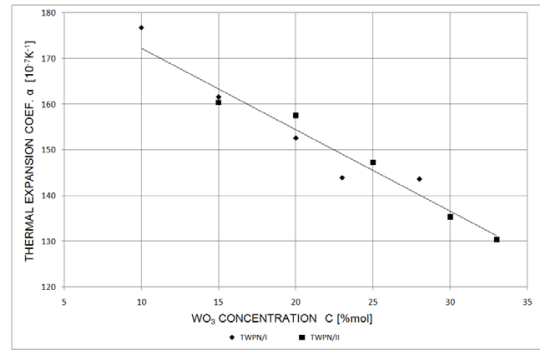

Fig. 3. $\mathrm{WO}_{3}$ concentration influence on thermal expansion coefficient of glasses in the temperature range $20 \div 300{ }^{\circ} \mathrm{C}$

If the viscosity range $10^{7} \div 10^{4} \mathrm{P}$ is considered, the forming temperature range is limited to $50^{\circ} \mathrm{C}$ for tellurite glasses, while the range is above $100^{\circ} \mathrm{C}$ for typical soft glasses.

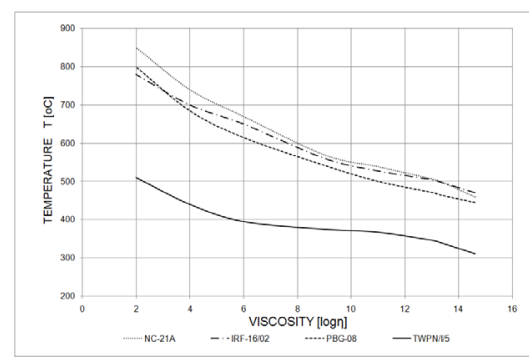

Fig.4. Viscosity curve of the TWPN/I/5 tellurite glass in comparison with curves for other kinds of glass manufactured at ITME: NC-21A (lithium-boro-silicate), IRF-16/02 (metaphosphate), PBG-08 (leadbismuth-silicate)

The Zwick microhardness meter is used for measurements of mechanical strength of tellurite glass under loading of $\mathrm{P}=0.2 \mathrm{kG}(1.96 \mathrm{~N})$. The obtained results demonstrate that tellurite glasses are mechanically very fragile. Their microhardness is comparable to heavy metal oxide glasses of the $\mathrm{PbO}-\mathrm{Bi}_{2} \mathrm{O}_{3}-\mathrm{GeO}_{2}$ system (PBG-04 glass) (Fig. 5). Their hardness is over half that of typical boro-silicate glasses (NC-21A and BK-7).

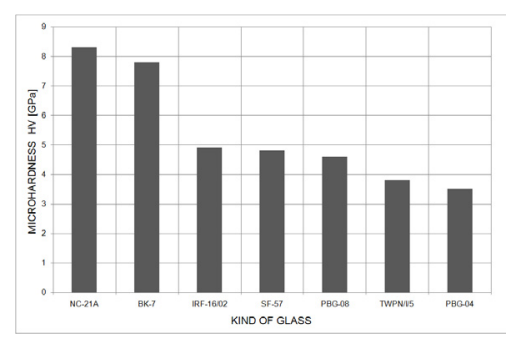

Fig.5. Microhardness of the TWPN/I/5 tellurite glass in comparison with other kinds of glass: NC-21A, BK-7 (Schott boro-silicate), IRF-16/02, SF-57 (Schott lead-silicate), PBG-08, PBG-04 (lead-bismuth-gallate)

The Differential Scanning Calorimetry method was used to select glasses with optimum thermal stability, where no exothermic effects are observed at DSC characteristics (Fig. 6 and 7). The summary of DCS measurements is presented in Table 2. Based on the obtained characteristics, the TWPN/I/6 $\left(25 \% \mathrm{WO}_{3}\right.$ i $0 \%$ $\mathrm{PbO}), \mathrm{TWPN} / \mathrm{II} / 3\left(25 \% \mathrm{WO}_{3}\right.$ i $\left.8 \% \mathrm{PbO}\right)$ and TWPN/II/4 
$\left(30 \% \mathrm{WO}_{3}\right.$ i $\left.3 \% \mathrm{PbO}\right)$ were selected for the development of PCFs.

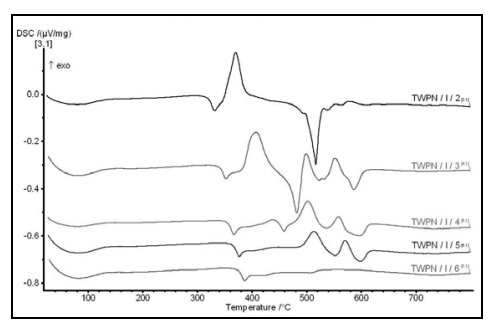

Fig. 6. DSC curves of the TWPN/I series tellurite glasses

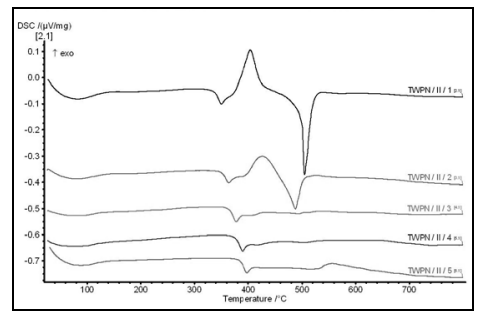

Fig.7. DSC curves of the TWPN/II series tellurite glasses

In addition, the glass TWPN/I/5 with chemical composition similar to TWNB-01 glass was also selected although the exothermic peak exists in this case (Fig. 6). Supplementary crystallization tests were successful for this glass. The absence of crystallization is related to a shift of the first exothermic peak into higher temperatures. Also in the case of the TWPN/II/5 glass that contains $33 \%$ of $\mathrm{WO}_{3}$ a weak exothermic peak is observed for a relatively high temperature of $556^{\circ} \mathrm{C}$ (Fig. 7). This glass can be also considered for PCF development since its exothermic peak is placed far from the temperatures of glass forming $\left(430 \div 465^{\circ} \mathrm{C}\right)$. The glass TWPN/II/5 also passed successfully the crystallization test.

\begin{tabular}{|c|c|c|c|}
\hline $\mathbf{T W P N / I} /$ & $\mathbf{T}_{\mathbf{g}}$ & $\mathbf{T}_{\mathbf{x}}$ & $\boldsymbol{\Delta} \mathbf{T}=\mathbf{T}_{\mathbf{x}} \mathbf{-} \mathbf{T}_{\mathbf{g}}$ \\
\hline $\mathbf{2}$ & 319,4 & 345,7 & 26,3 \\
\hline $\mathbf{3}$ & 340,6 & 377,5 & 36,9 \\
\hline $\mathbf{4}$ & 354,9 & 414,0 & 59,1 \\
\hline $\mathbf{5}$ & 364,9 & 476,0 & 111,1 \\
\hline $\mathbf{6}$ & 374,5 & 506,0 & 131,5 \\
\hline $\mathbf{T W P N} / \mathbf{I I} /$ & $\mathbf{T}_{\mathbf{g}}$ & $\mathbf{T}_{\mathbf{x}}$ & $\boldsymbol{\Delta} \mathbf{T}=\mathbf{T}_{\mathbf{x}} \mathbf{-} \mathbf{T}_{\mathbf{g}}$ \\
\hline $\mathbf{1}$ & 337,5 & 366 & 28,5 \\
\hline $\mathbf{2}$ & 351,0 & 390 & 39,0 \\
\hline $\mathbf{3}$ & 365,1 & 528 & 162,9 \\
\hline $\mathbf{4}$ & 374,5 & 529 & 154,5 \\
\hline $\mathbf{5}$ & 384,5 & 524 & 139,5 \\
\hline
\end{tabular}

Table 2.Characteristic temperatures for tellurite glasses calculated based on DSC measurements

We have observed that the replacement of $\mathrm{WO}_{3}$ with $\mathrm{PbO}$ reduces the thermal stability of glasses in the considered $\mathrm{TeO}_{2}-\mathrm{WO}_{3}-\mathrm{PbO}-\mathrm{Na}_{2} \mathrm{O}-\mathrm{Nb}_{2} \mathrm{O}_{5}$ system. A concentration of $3 \div 8 \mathrm{~mol} \% \mathrm{PbO}$ in the case of total contents of $33 \mathrm{~mol} \%$ of $\mathrm{WO}_{3}$ and $\mathrm{PbO}$ is suitable for fiber development (tellurite glasses series TWPN/II, 60mol\% $\mathrm{TeO}_{2}$ ). In addition, a maximum concentration of $33 \mathrm{~mol} \%$ $\mathrm{WO}_{3}$ is still acceptable when the concentration of $\mathrm{PbO}$ is $0 \%$ (TWPN/II/5 glass), since spontaneous crystallization is observed for $38 \%$ contents of $\mathrm{WO}_{3}$ (TWPN/II/6 glass).

A preliminary developed TWNB-01 glass was used for fiber development. We have developed tubes and rods using the casting method followed by mechanical polishing. The tubs are cast in a graphite casting form with a metal rod in the center. After the annealing process the casting form is opened and the glass is further mechanically processed. The final diameter rods and tubes were drawn with a fiber optic drawing tower (Fig. 8). The structure of the fiber was designed as a hexagonal lattice with 15 capillaries on the diagonal. A solid elliptical core was created by omitting two central capillaries. The photonic cladding was built by 6 rings of holes. A filling factor of $\mathrm{d} / \Lambda=0.64$ was obtained in the fiber. For optical testing we used the fiber with a lattice constant of $\Lambda=1.48 \mu \mathrm{m}$ and a hole diameter of $\mathrm{d}=0.95 \mu \mathrm{m}$. The elliptical core diameters were $1.71 \mu \mathrm{m}$, and $3.80 \mu \mathrm{m}$ (Fig. 8c).

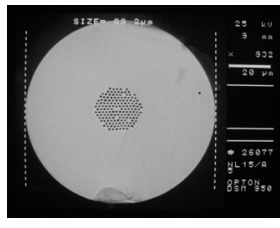

$a$

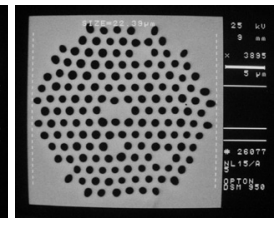

$b$

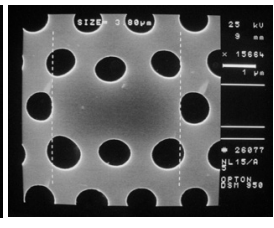

$c$
Fig. 8. A cross-section of a tellurite PCF made of TWNB-01 glass

The fiber is not properly characterized in terms of optical properties since an additional unintended core is created during the final drawing (Fig. $8 \mathrm{a}$ and $8 \mathrm{~b}$ ). Nevertheless, a strong localization of light in the core and light guidance was observed. The preliminary experiment is performed with a Ti:Sapphire laser at $810 \mathrm{~nm}$ in the $\mathrm{CW}$ regime. The successful transfer of a high power beam of $618 \mathrm{~mW}$ without any fiber damage is completed.

This work is supported by the Ministry of Science and Higher Education under grant No N N 507433934.

\section{References}

[1] T.M.Monro and H.Ebendorff-Heidepriem, Rev. Mater. Res. 36, 467-495 (2006).

[2] D.Lorenc, M.Aranyosiova, R.Buczynski, R.Stepien, I.Bugar, A.Vincze, D.Velic, Applied Physics B: Lasers and Optics, 93, 531538 (2008).

[3] V.V.Ravi Kanth Kumar, A.K.George, J.C.Knight, and P.S.J. Russell, Opt. Express 11, No 20, 2641-2645 (2003)

[4] D.A.Gaponov, A.S.Biryukov, Quantum Electron 36(4), 343-348 (2006).

[5] E.F.Chillcce, C.M.B.Cordeiro, L.C.Barbosa, C.H. Brito Gruz, J.Non-Cryst.Solids 352, 3423-3428 (2006). 